\title{
Thermal analysis of polyurethane elastomers matrix with different chain extender contents for thermal conductive application
}

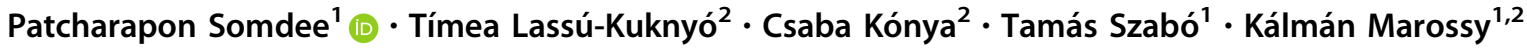

Received: 20 May 2018 / Accepted: 10 March 2019/Published online: 23 March 2019

(C) The Author(s) 2019

\begin{abstract}
Polyurethane elastomers (PUR) based on polypropylene glycol and 4,4'-diphenylmethane diisocyanate were prepared with various monoethylene glycol (mEG) contents. The aim of this study is to find a reliable polymer matrix for composites of improved thermal conductivity and testing fully in order to collect knowledge about its structure. Thermal conductivity was improved from 0.255 to $0.329 \mathrm{~W} \mathrm{~m}^{-1} \mathrm{~K}^{-1}$ when increasing chain extender content. This attributed to a high appearance crystalline ordering level when adding high $\mathrm{mEG}$ content. Differential scanning calorimetry revealed a low transition temperature of soft segment at the same temperature around $-64{ }^{\circ} \mathrm{C}$, due to constant polyol content. The enthalpy of melting increases with increasing $\mathrm{mEG}$ content. This is due to the increasing crystalline phase and hard segment phase separation within the PUR structure. Dynamic mechanical analysis results show the glass transition temperature of soft segment in the same temperature range between -57 and $-52{ }^{\circ} \mathrm{C}$ and intensity peak of $\tan \delta$ tends to decrease when mEG content was increased. On the other hand, the glass transition temperature of hard segment tends to increase from 10 to $93{ }^{\circ} \mathrm{C}$ and has high intensity peak of $\tan \delta$ with increasing mEG content. Increasing the chain extender content can be enhancing the hard segment length in PUR structure and affecting both soft segment motion and hard segment motion. Increasing hard segment length might be obstructing soft segment motion and influence hard segment motion which is hard to move at low temperatures. Phase separation of soft and hard segment clearly observed using the DMA technique.
\end{abstract}

Keywords Polyurethane elastomers - Chain extender $\cdot$ Structural polymer $\cdot$ Thermal analysis

\section{Introduction}

Polyurethanes are widely used in industry and have wide range of applications. Polyurethanes have several advantages consisting of high impact strength, good elasticity, high elongation, abrasion resistance, excellent resistance to oils and solvents, good tear resistance and so on [1]. However, polyurethanes have low thermal conductivity, hence many efforts trying to improve their properties and especially thermal conductivity. Polyurethanes are organic polymers that contain the urethane groups in their structure. They are typically made by the reaction of a polyol with a

Patcharapon Somdee

somdee_patch@hotmail.com

1 Ceramic and Polymer Engineering Institute, University of Miskolc, Miskolc, Hungary

2 BorsodChem Zrt., Kazincbarcika, Miskolc, Hungary diisocyanate. It contains two separate structural phases consisting of a hard segment and a soft segment. Polyol structure is related to the reaction of diisocyanate with hydroxyl groups of chain extender and polyol. Elastomeric behavior of polymeric systems can be attributed to microphase separation of the hard and soft segments. The rigid domains reinforce the elastomeric matrix like covalent linkages in cross-linked elastomers. Consequently, the effective parameters on the properties of PUR are soft segmental chemical construction, hard segmental chemical construction and relative size between the soft and hard segments. The chemical constructions of segments are related to the type of polyols, diisocyanate and chain extenders used in the composition. Furthermore, the last factor changes with the choice of different molar ratios of raw materials [2]. Thermal conductivity can be determined by the structure of the polymer as well as the morphology of the polymer. There is a large scatter in the reported experimental data of thermal conductivity of crystalline 
polymers. It should be noticed that the thermal conductivities of polymers depend on many factors such as chemical constituents, bond strength, structure type, side group molecular weight, molecular density distribution, type and strength of defects or structural faults, size of intermediate range order, processing conditions and temperature [3].

Chain extenders are reactive low molecular weight compounds such as hydroxyl amines, glycols and other types, and diamines are used to influence the end properties of polyurethanes during their synthesis [4]. Two main groups are used as chain extenders such as aromatic diols or diamines and the corresponding aliphatic diols or diamines. The choice of a chain extender depends on the properties required and the process conditions. Chain extender may increase the hard segment length to allow hard segment segregation which results in good mechanical properties such as an increase in modulus and the hard segment glass transition temperature of polyurethane [5-14]. In general, PUR chain extended with an aliphatic diol to produce a softer material than do their aromatic chain extended counterparts. Also, diamine chain extenders are much more reactive than diol chain extenders and give properties superior to those of similar polymers prepared with the equivalent diol chain extenders. This is due to the hard segment (urea linkage) which has a higher density of hydrogen bonding, resulting in a higher glass transition temperature and higher thermal stability. Moreover, due to electron delocalization in the aromatic chain extenders, they have less reactivity than aliphatic chain extenders which can be favorable in reactions that need to be highly controlled [15]. There were several works explaining about the effect of chain extenders in PUR properties. For example, effect of chain extender on mechanical properties of PUR was investigated. Tensile strength was increased by the ethylene glycol but had negative influenced on the elongation at break [16]. Ethylene glycol was used as chain extender in polyurethanes synthesis. The formula has affected the polyurethane's properties, like density, impact resilience, compression set, water absorbency behavior and cellular morphology a great deal in comparison. Results show these properties are dependent on the chain extender content in the polyurethane compound [17]. Butanediol shows properties superior to other extenders. The superior performance of butanediol as an extender can be explained on the basis of structural regularity formed by the acid component in the polyester [18]. Chain extender type and urethane group content on the mechanical properties was studied. The best mechanical behavior as elastomers was achieved for polyurethanes with even numbers of $\mathrm{CH}_{2}$ on the chain extender, so the different parts of PUR macromolecular chains can adopt extended linear forms [4]. Elastomers with larger chain extender molecular have larger hard segments and better phase separation. The ratio of the hard to soft segment content has effects on phase separation, good physical and mechanical properties [2, 4]. The effect of the incorporation of various new chain extenders on mechanical and thermal properties of PUR was examined. Longer chain lengths between cross-links produce higher elongations at break and lower modulus. The branched chains of the difunctional chain extenders decrease the physical cross-link density and thus decrease in the mechanical strength. The cross-linking process increases the urethane domain's rigidity and decreases the soft segment's crystallinity. These factors enhance the tensile strength of the materials [15]. The glass transition temperature of materials increases with increasing hard segment content. Interchain cross-linking improves thermal stability. The structure and amount of hard segments cause a significant variation in the properties of cross-linked elastomers [19]. Effect of the chemical nature of chain extender on both phase separation and final properties of the polyurethane dispersions was also examined. Diols are used as chain extenders. A higher degree of crystallinity in the polyurethane structure is obtained due to the increased phase separation because of increasing the chain extender length which produces an increase in the adhesion values when molecular weight of the chain extender is increased [11]. A systematic investigation is made on the effect of the chemical structure of chain extenders on the physical and thermal properties of polyurethanes [20]. Spectroscopic, mechanical and thermal data reveal that polymer properties can be significantly altered by differences in chemical bonding within the chain extender's backbone. Although all data support the expected differences in phase morphology between the two series of samples, they also suggest that increasing the chain extender's unsaturation reduced its reactivity with isocyanate, also adversely affected hydrogen bonding, lowered the degree of crystallinity of the hard segments and decreased phase separation [21]. Thermal and mechanical properties are discussed from the viewpoint of microphase domain separation of hard and soft segments. It resulted in negative deviation in the modulus of the polymers. It may be due to the bulky structure and strong cohesive force of the urea groups [22].

From previous studies about the effect of chain extender, thermal conductivity and structural PUR with varying chain extender content were investigated in order to flexible and rigid PUR application by thermal conductivity test, differential scanning calorimetry (DSC) and dynamic mechanical analysis (DMA) method. 


\section{Experimental}

\section{Materials}

PUR were synthesized using polypropylene glycol (PPG4000) for polyol which reacted with ethylene oxide (ALCUPOL D4011). 4,4'-Diphenylmethane diisocyanate (MDI) was used for isocyanate. Trade name of MDI is ONGRONAT XP 1147. It is an acidified MDI blend based on ONGRONAT 2100, MI50 and pure MDI. Average molecular weight is $266 \mathrm{~g} \mathrm{~mol}^{-1}$, and equivalent weight is $127.33 \mathrm{~g} \mathrm{~mol}^{-1}$. In this study, monoethylene glycol (mEG) is used for chain extender. It is produced from ethylene by the intermediate ethylene oxide. Ethylene oxide reacts with water to produce ethylene glycol. DABCO $33-\mathrm{LV}$ is a catalyst in this study, mixture of $33 \%$ triethylene diamine and 67\% dipropylene glycol. The air release additive is BYK A500, silicone-free air release additive. Furthermore, two types of moisture scavenger are used that consist of Finmasorb $430 \mathrm{PR}$ and Incozol LV. Finmasorb $430 \mathrm{PR}$ is a molecular sieve pasted in castor oil at 50\%, and Incozol LV also acts as a moisture scavenger preventing the generation of $\mathrm{CO}_{2}$ gas. All of ingredients are listed in Table 1.

\section{Methods}

Polyol blends were prepared by solution sheared mix with different chain extender contents from 7 to $34 \mathrm{~g}$. Moreover, amine catalyst, air release additive and two moisture scavengers were also solution mixed with the polyol. Then, polyol blend was mixed with MDI part by mass fraction as shown in Table 1. The polyol blend was homogenized using homogenization machine and pre-dried. After that, an acidified MDI blend was added in the polyol blend and shear mixed for 20-25 s at around $1000 \mathrm{rpm}$ and poured into the warm mold of $50{ }^{\circ} \mathrm{C}$ at least $30 \mathrm{~min}$ to form a homogeneous PUR sheet of 1-4 mm thickness. The cured sample sheets were stored for at least 3 days at room temperature before testing. Structural PUR were characterized by DSC technique. DSC of PUR was performed on
METTER TOLEDO model DSC823e with heating rate of $10{ }^{\circ} \mathrm{C} \mathrm{min}{ }^{-1}$ from -100 to $250{ }^{\circ} \mathrm{C}$. Sample mass of around $10 \mathrm{mg}$ was used, accurately shown in Fig. 3 . Dynamic Mechanical Thermal Analyzer MkIII (Rheometric Scientific) was used for DMA tests from -80 to $150{ }^{\circ} \mathrm{C}$ with heating rate of $2{ }^{\circ} \mathrm{C} \mathrm{min}{ }^{-1}$. The measurement was taken in bending mode at $1 \mathrm{~Hz}$. Thermal conductivity was measured by C-THERM thermal conductivity analyzer (TCi), and the density of PUR was also measured.

\section{Results and discussion}

\section{Thermal conductivity and density}

Thermal conductivity of PUR with different mEG contents was measured using a TCi Thermal Conductivity Analyzer (C-THERM). Each sample was placed on the sensor and measured at room temperature. A known current is applied to a spiral heating element of the sensor, providing a small amount of heat. This results in a rise in temperature at the interface between sensor and sample which induces a change in the voltage drop of the sensor element. The rate of increase in the sensor voltage is used to determine the thermophysical properties of the sample. The thermophysical properties are inversely proportional to the rate of increase in the sensor voltage. Result shows the variation of thermal conductivity tends to increase with increasing content of mEG chain extender. The highest thermal conductivity is observed at $34 \mathrm{~g}$ mEG of $0.329 \mathrm{~W} \mathrm{~m}^{-1} \mathrm{~K}^{-1}$. Thermal conductivity enhanced around $29 \%$ when compared to $7 \mathrm{~g}$ mEG content as shown in Fig. 1 and Table 2 . This may be due to increasing the crystallinity level when mEG content was increased by cross-linking. The other reason might be due to polymer crystallinity strongly affecting their thermal conductivity. The hard segment content also influences the physical properties of polyurethanes [16]. Besides, thermal stability of the polymer is connected to their chemical structure, the bond energy between individual atoms comprising the material (energy of dissociation into radicals) [3]. Furthermore, the increase
Table 1 Ingredients of polyurethane elastomers

\begin{tabular}{lll}
\hline Description & Trade name & Mass/g \\
\hline Polypropylene glycol (PPG-4000) & ALCUPOL D4011 & 100 \\
Monoethylene glycol & mEG & $7,10,22,30,34$ \\
Catalyst & Dabco 33-LV & $0.15,0.3$ \\
Air release additive & BYK A500 & 2 \\
Moisture scavenger & Finmasorb 430 PR & 5 \\
Moisture scavenger & Incozol LV & 2.5 \\
$4,4^{\prime}$-Diphenylmethane diisocyanate (MDI) & ONGRONAT XP 1117 & $24-52^{\mathrm{a}}$ \\
\hline
\end{tabular}

${ }^{a}$ Varying with the other ingredients to keep the content of $\mathrm{NCO}: \mathrm{OH}$ ratio 


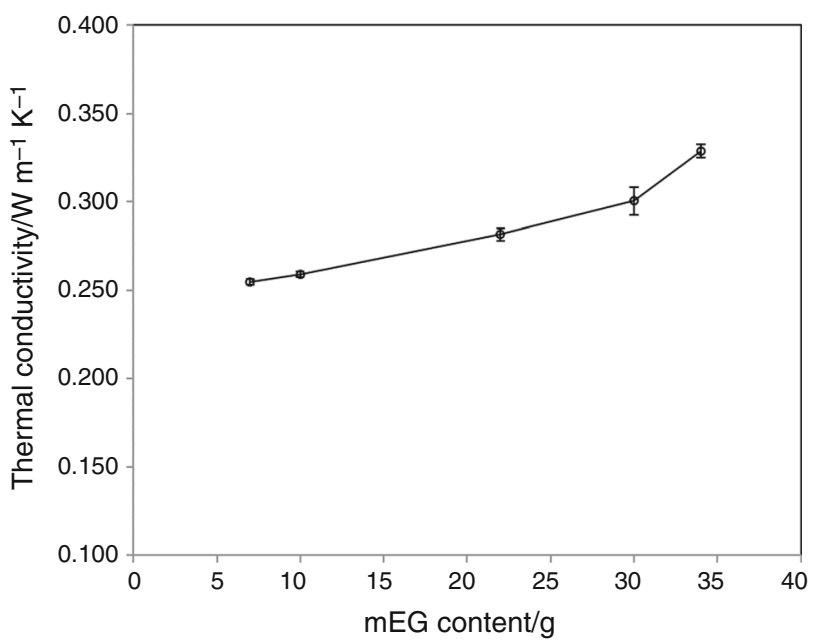

Fig. 1 Thermal conductivity of polyurethane elastomers with various $\mathrm{mEG}$ contents from 7 to $34 \mathrm{~g}$

in thermal conductivity related to the increase in density as shown in Fig. 2 and Table 2. Density increases because mEG more easily reacts with MDI and PPG polyol, especially the hard segment in PUR structure and due to the hard segment (urea linkage) which has a higher density of hydrogen bonding [15].

\section{Differential scanning calorimetry (DSC) measurement}

To investigate the crystalline phases in PUR microstructure that are formed by the hard segments and soft segments, DSC analysis has been used. DSC curves from the first heating scans of PUR with different $\mathrm{mEG}$ contents from 7 to $34 \mathrm{~g}$ are shown in Fig. 3. The first heating scans of all the PUR show glass transition of soft segment in the same temperature of about $-64{ }^{\circ} \mathrm{C}$ when mEG content was increased as shown in Table 3. However, a relaxation transition could not clearly be observed at high chain extender contents. This may be due to that the cross-linking of the hard segments obscures the PPG polyol segment's motion, which leads to having less soft segments with ordered structures or crystals [15] so they are not clearly registered especially at chain extender contents of 30 and $34 \mathrm{~g}$. The broad endotherms peak at mEG content of $7 \mathrm{~g}$ can be suggested to be related to a small degree of ordering

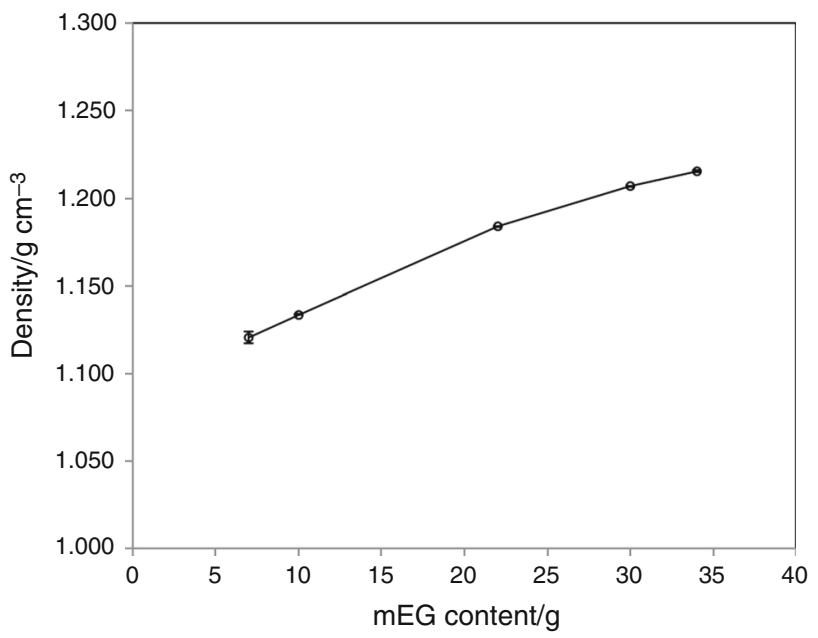

Fig. 2 Density of polyurethane elastomers with various mEG contents from 7 to $34 \mathrm{~g}$

in the hard segment domains. DSC curves reveal a higher degree of the hard segment ordering that exhibited by the presence of endothermic peaks [23, 24]. In case of high mEG contents, endotherm peaks have narrower and higher intensity than the one related to soft segments that may be due to it having higher hard segment contents with more cross-linking than at lower $\mathrm{mEG}$ contents.

Figure 4 shows the first derivative of the melting curves of PUR with different $\mathrm{mEG}$ contents from flexible to rigid. The first derivative curve of a glass transition gives a peak which area is proportional to the value of $\Delta C_{\mathrm{p}}$. Peak temperature of the first derivative can be used as a measure of change in glass transition temperature. Therefore, the first derivative curves show the glass transition temperature of the soft segments as the same temperature from DSC curve of $-64^{\circ} \mathrm{C}$. Furthermore, Table 3 shows enhancement of enthalpy of melting. The enthalpy of melting tends to increase with increasing $\mathrm{mEG}$ content. This reveals that the crystalline phase was increased with increasing chain extender content and improved the hard segment phase separation in the PUR structure. Low $\Delta H_{\mathrm{m}}$ values at $\mathrm{mEG}$ content of $7 \mathrm{~g}$ of the endothermic peak indicated the remaining the amorphous structures [25]. Glass transition temperature of hard segment $\left(T_{\mathrm{g}, \mathrm{HS}}\right)$ is in the range of $58-70{ }^{\circ} \mathrm{C}$. The chain extender content did not have significant effect on $T_{\mathrm{g}, \mathrm{HS}}$ on DSC measuring. However, the
Table 2 Thermal conductivity and density of polyurethane elastomers with different $\mathrm{mEG}$ contents

\begin{tabular}{lll}
\hline $\mathrm{mEG}$ content/g & Thermal conductivity/ $/ \mathrm{W} \mathrm{m}^{-1} \mathrm{~K}^{-1}$ & Density/g cm \\
\hline 7 & $0.255 \pm 0.002$ & $1.120 \pm 0.003$ \\
10 & $0.259 \pm 0.002$ & $1.134 \pm 0.000$ \\
22 & $0.282 \pm 0.003$ & $1.184 \pm 0.000$ \\
30 & $0.301 \pm 0.008$ & $1.207 \pm 0.000$ \\
34 & $0.329 \pm 0.004$ & $1.215 \pm 0.000$ \\
\hline
\end{tabular}




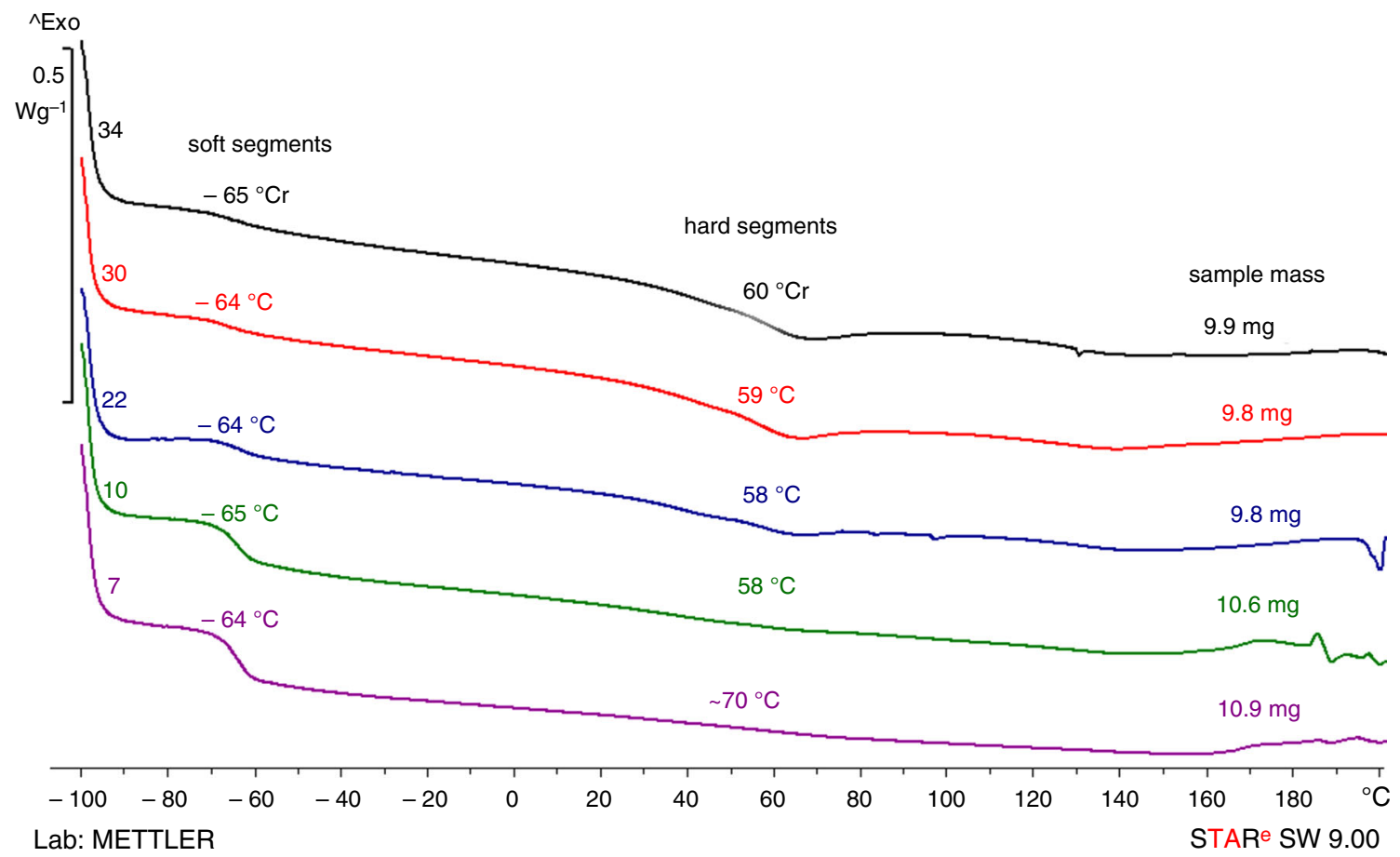

Fig. 3 DSC curves of polyurethane elastomer with various $\mathrm{mEG}$ contents from 7 to $34 \mathrm{~g}$

Table 3 Thermal properties of polyurethane elastomers with different $\mathrm{mEG}$ contents

\begin{tabular}{|c|c|c|c|c|c|c|}
\hline \multirow[t]{2}{*}{$\mathrm{mEG}$ content/g } & \multicolumn{4}{|l|}{ DSC } & \multicolumn{2}{|l|}{ DMA } \\
\hline & $T_{\mathrm{g}, \mathrm{sS}}{ }^{\circ} \mathrm{C}$ & $T_{\mathrm{g}, \mathrm{HS}} /{ }^{\circ} \mathrm{C}$ & $T_{\text {endotermic }} /{ }^{\circ} \mathrm{C}$ & $\Delta H_{\mathrm{m}} / \mathrm{J} \mathrm{g}^{-1}$ & $T_{\mathrm{g}, \mathrm{sS}} /{ }^{\circ} \mathrm{C}$ & $T_{\mathrm{g}, \mathrm{HS}} /{ }^{\circ} \mathrm{C}$ \\
\hline 7 & -64 & $\sim 70$ & N/A & N/A & -56 & 10 \\
\hline 10 & -65 & 58 & 62 & 2.48 & -57 & 28 \\
\hline 22 & -64 & 58 & 64 & 2.76 & -54 & 73 \\
\hline 30 & -64 & 59 & 65 & 9.54 & -57 & 84 \\
\hline 34 & -65 & 60 & 67 & 10.02 & -52 & 93 \\
\hline
\end{tabular}

glass transition temperature of hard segment is difficult which is evaluated by DSC technique because the first derivative shows very small transition.

\section{Dynamic mechanical analysis (DMA) measurement}

Dynamic mechanical analysis provides information on viscoelastic properties. The storage modulus $\left(E^{\prime}\right)$ provides information regarding the stiffness of the materials, while the loss tangent $(\tan \delta)$ measures the degree of molecular motion. The glass transition temperature of the soft segment is defined as the $\alpha$ transition in the $\tan \delta$ curve. Significant features of a $\tan \delta$ plot include the location of the low-temperature maximum where smaller areas are associated with better phase separation of PUR hard and soft phases, as well as less of the hard phase being involved in the glass transition. The magnitude of $\tan \delta$ across the application temperature is proportional to the ratio of energy absorbed as heat by sample to energy returns as movement of the sample [5].

The storage modulus and $\tan \delta$ of PUR with different chain extender contents are in the temperature range between -70 and $140{ }^{\circ} \mathrm{C}$ as shown in Figs. 5 and 6. The $E^{\prime}$ with various $\mathrm{mEG}$ contents is very hard at start temperature, and then, it decreases at low temperatures around $-60{ }^{\circ} \mathrm{C}$, and $\tan \delta$ shows a peak associated with the glass transition temperature of the soft segment at the same temperature range between -57 and $-52{ }^{\circ} \mathrm{C}$ as shown in Table 3. However, intensity of $\tan \delta$ peak of soft segment tends to decrease with increasing $\mathrm{mEG}$ content. This is due to low degree of PPG polyol segment motion which relates to DSC curve hard to evaluate a small relaxation of PUR chain at high mEG content. It may be due to the high degree of cross-linking reducing the mobility of the soft segment [26, 27].

In case of high temperature, $\tan \delta$ results exhibit a shift in the curve to higher temperatures and also broadening and 
$\wedge$ Exo

34

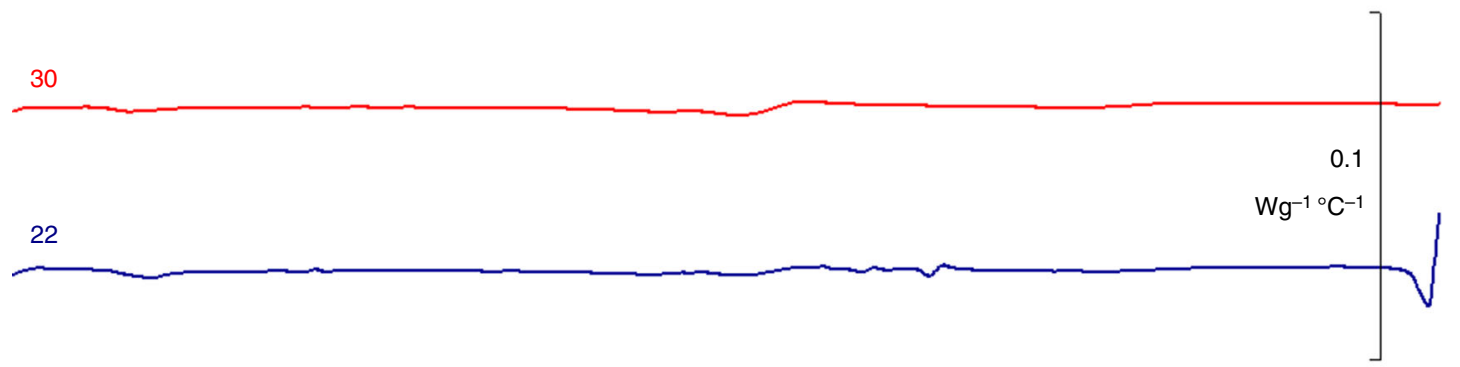

10
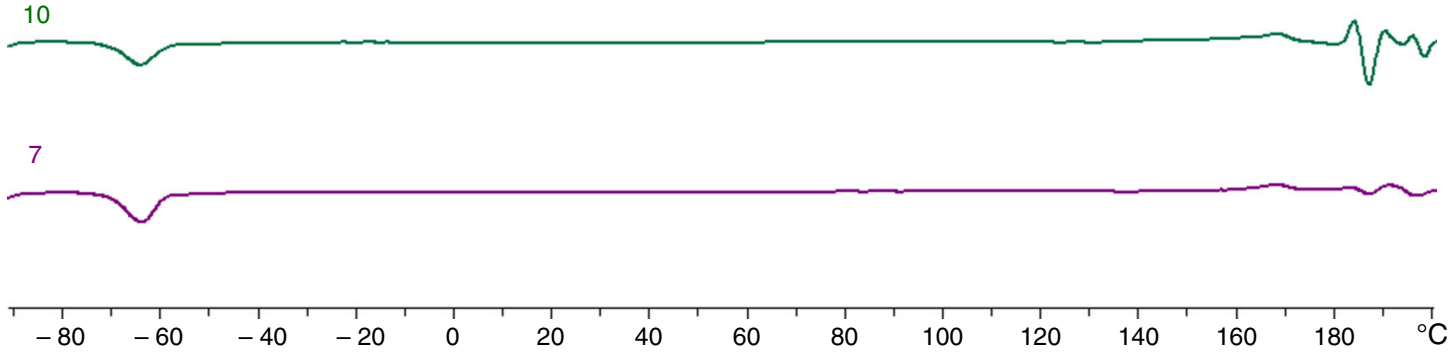

Lab: METTLER

STAR ${ }^{\text {SW }} 9.00$

Fig. 4 First derivative from DSC curves of polyurethane elastomer with various $\mathrm{mEG}$ contents from 7 to $34 \mathrm{~g}$

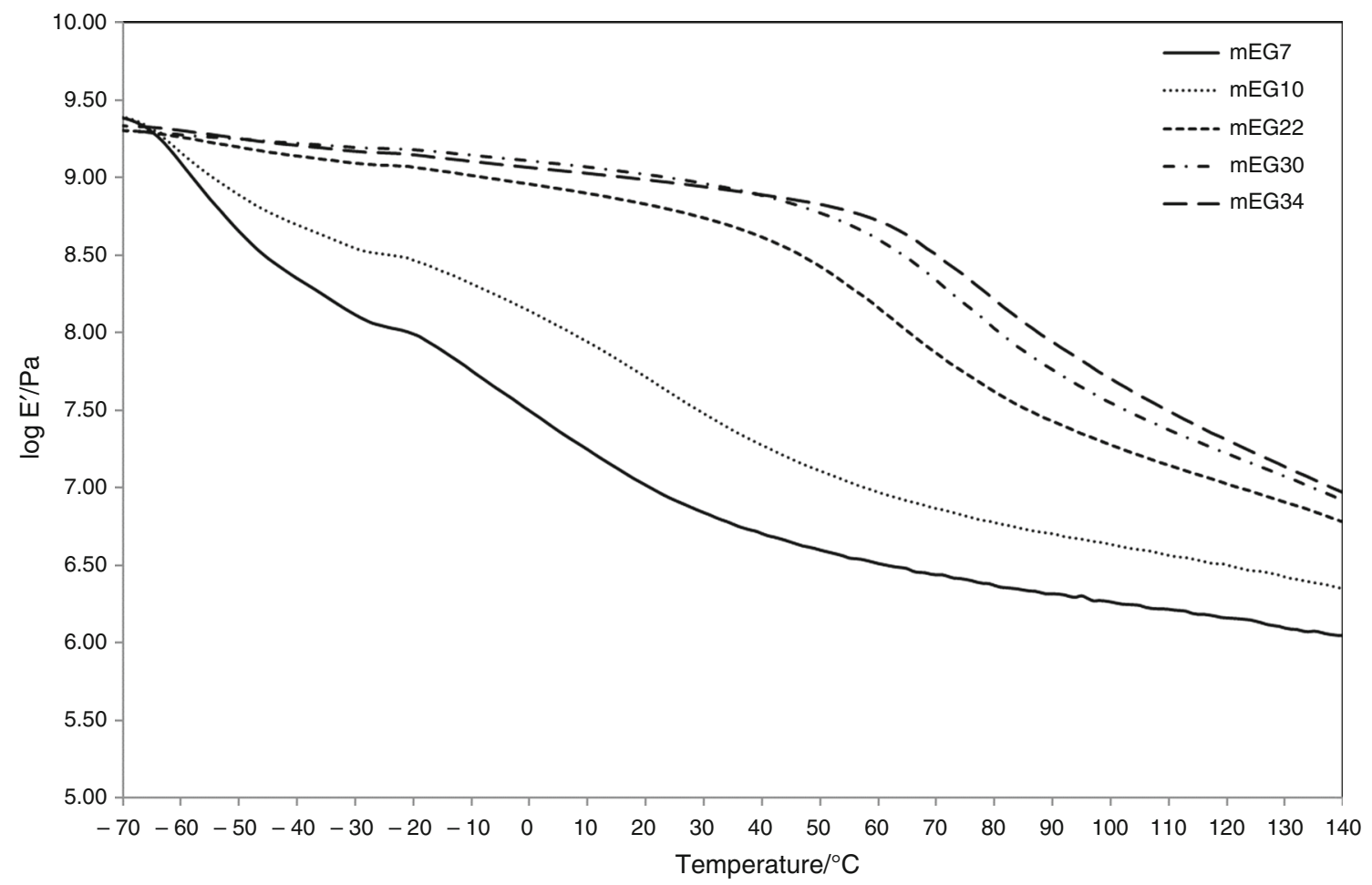

Fig. 5 Storage modulus from DMA of polyurethane elastomers with various mEG contents from 7 to $34 \mathrm{~g}$

high intensity of the peaks with increasing chain extender content as shown in Fig. 6. Table 3 shows the glass transition temperature of hard segment tends to increase with increasing chain extender content. This increase in melting point is may be due to the increase in the number of higher length hard segment chains in the hard segment domains 


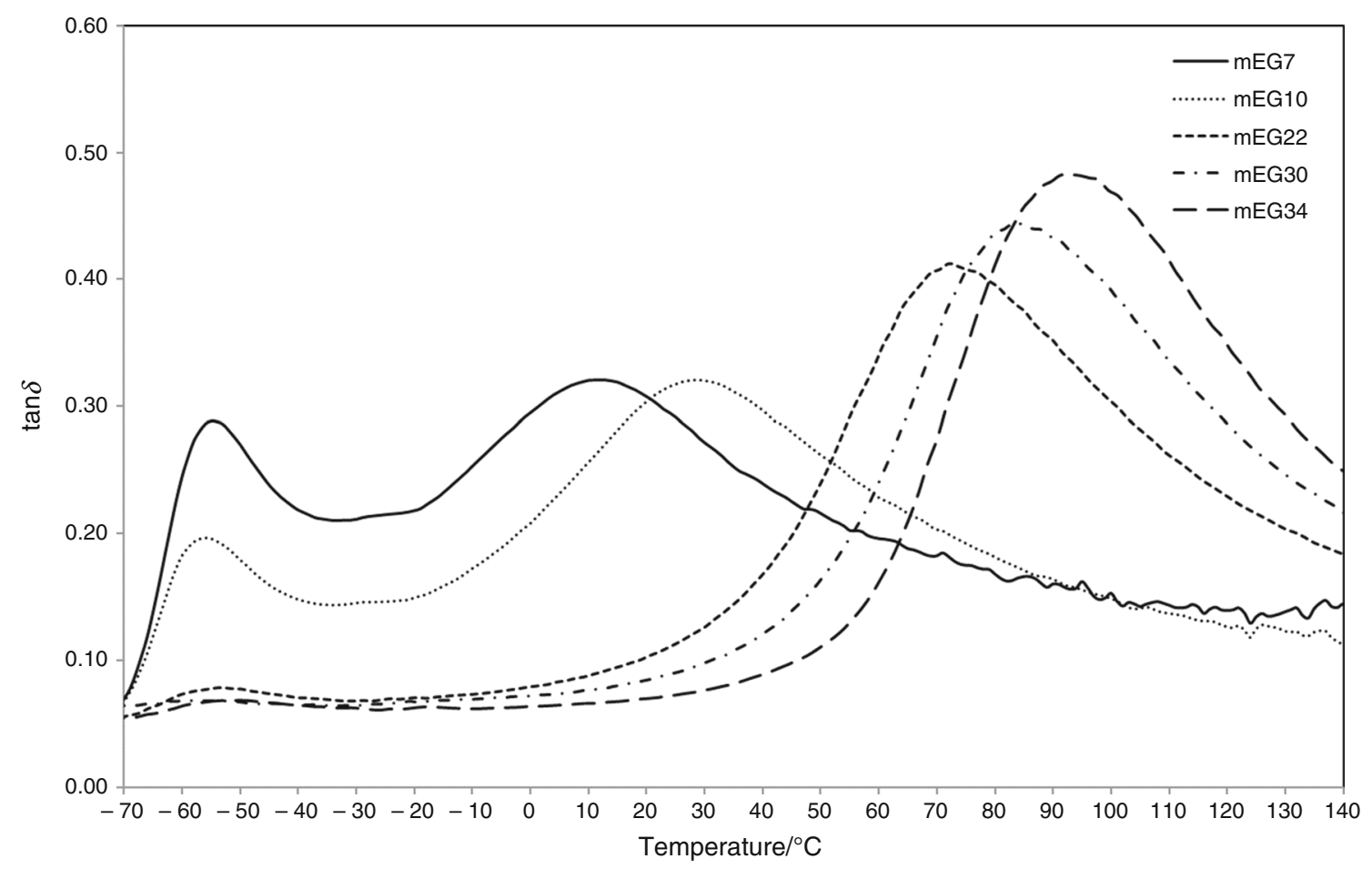

Fig. 6 Mechanical loss factor from DMA of polyurethane elastomers with various mEG contents from 7 to $34 \mathrm{~g}$

that occur as the hard segment content of the polymer is increased [20] and attributed to increasing hard segment crystallinity [28] and phase separation which tend to reduce soft segment mobility. The increasing hard segment resulted in larger hard microcrystalline domains that restricted the molecular motion of the soft segment [5]. Furthermore, the polymer chain with longer chain extender has longer hard segment. The length of hard segment has also effect on phase separation [15].

For flexible PUR at mEG content of 7 and $10 \mathrm{~g}, E^{\prime}$ shows two rubbery regions. The first region at lower temperature from -65 to $-29{ }^{\circ} \mathrm{C}$ is mainly elastic. After that, $E^{\prime}$ decreases continually with increasing the temperature. This reveals that the hard segments are not able to form a sufficient amount of physical cross-links. $E^{\prime}$ of PUR starts to be elastic again at around $-10{ }^{\circ} \mathrm{C}$. Anyway, mEG content of $10 \mathrm{~g}$ exhibits higher $E^{\prime}$ value than of $7 \mathrm{~g}$ although there is the same pattern. This is due to the high cross-linking of hard segment in PUR structure which affects chain mobility of molecular chain. In case of rigid PUR at high mEG content, storage modulus slightly decreases when temperature was increased at around $40{ }^{\circ} \mathrm{C}$ as shown in Fig. 5. Then, it rapidly decreases which can be indicated as melting of the hard segment phases and physical and chemical cross-linking sites between hard segments are totally destroyed [15].

\section{Conclusions}

Increasing chain extender content can be increased thermal conductivity of polyurethane elastomers (PUR) because of increasing the crystallinity level by cross-linking in PUR structure. This can be related to a slight increase in density.

Structural phase separation of PUR can be observed from a small relaxation of soft segment hard to evaluate when chain extender content was increased, while the enthalpy of melting tends to increase. These reveal that they gave better hard segment phase although the glass transition of hard segment did not clearly observe in DSC curve.

DMA results both storage modulus and $\tan \delta$ show high hard segment from the cross-linking of chain extender that reacted to isocyanate part in PUR. The glass transition temperature of soft segment did not significantly change, but the intensity of $\tan \delta$ peak tends to decrease with increasing chain extender content. This may be due to a low degree of PPG polyol segment motion. On the other hand, the glass transition temperature of hard segment can be observed and tend to increase when chain extender content was increased. This may be due to increasing the length hard segment chains in the hard segment domains. Flexible PUR show two rubbery regions and lower storage modulus than PUR at high chain extender content. This can also be attributed to high cross-link of hard segment in 
PUR structure which affects chain mobility of molecular chain and phase separation.

Acknowledgements Open access funding provided by University of Miskolc (ME). This research is carried out as part of EFOP-3.6.1-162016-00011 "Younger and Renewing University-Innovative Knowledge City-institutional development of the University of Miskolc aiming at intelligent specialisation" project implemented in the framework of the Szechenyi 2020 program. The realization of this project is supported by the European Union, co-financed by the European Social Fund. The research was supported by BorsodChem Zrt. Company and was partially carried out from Institute of Ceramic and Polymer Engineering.

Open Access This article is distributed under the terms of the Creative Commons Attribution 4.0 International License (http://creative commons.org/licenses/by/4.0/), which permits unrestricted use, distribution, and reproduction in any medium, provided you give appropriate credit to the original author(s) and the source, provide a link to the Creative Commons license, and indicate if changes were made.

\section{References}

1. Sharmin E, Zafar F. Title of subordinate document. In: Polyurethane: an introduction. InTech. 2012. https://www.intechopen. com/books/polyurethane/polyurethane-an-introduction. Accessed 5 Mar 2018.

2. Barikani M, Barmar M. Thermoplastic polyurethane elastomers: synthesis, and study of effective structural parameters. Iran Polym J. 1996;5(4):231-5.

3. Liszkowska J, Czupryński B, Paciorek-Sadowska J. Thermal properties of polyurethane-polyisocyanurate (PUR-PIR) foams modified with tris(5-hydroxypenthyl) citrate. J Adv Chem Eng. 2016. https://doi.org/10.4172/2090-4568.1000148.

4. Prisacariu C, Scortanu E. Influence of the type of chain extender and urethane group content on the mechanical properties of polyurethane elastomers with flexible hard segments. High Perform Polym. 2011. https://doi.org/10.1177/0954008311405696.

5. Prisacariu C. Polyurethane elastomers: from morphology to mechanical aspects. Wien: Springer; 2011.

6. Moon S-Y, Park Y-D, Kim C-J, Won CH, Lee Y-S. Effect of chain extenders on polyurethanes containing both Poly(butylene succinate) and poly(ethylene glycol) as soft segments. Bull Korean Chem Soc. 2003;24(9):1361-4.

7. Tan $C$, Tirri $T$, Wilen C-E. Investigation on the influence of chain extenders on the performance of one-component moisture-curable polyurethane adhesives. Polymers. 2017. https://doi.org/10. 3390/polym9050184.

8. Kultys A, Puszka A. New thermoplastic polyurethane elastomers based on sulfur-containing chain extenders. Pol J Chem Technol. 2013;15(4):65-70.

9. Chattopadhyay DK, Sreedhar B, Raju KVSN. Effect of chain extender on phase mixing and coating properties of polyurethane ureas. Ind Eng Chem Res. 2005;44:1772-9.

10. Kalajahi AE, Rezaei M, Abbasi F, Sadeghi GMM. The effect of chain extender type on the physical, mechanical and shape memory properties of poly ( $\varepsilon$-caprolactone)-based polyurethaneureas. Polym Plast Technol Eng. 2017. https://doi.org/10.1080/ 03602559.2017.1298797.

11. Elena O-C, Francisca A-A, Ana MT-P, César O-B. Characterization of polyurethanes containing different chain extenders. Prog Rubber Plast Recycl Technol. 2011;27(3):145-60.
12. Oprea S. Effect of the long chain extender on the properties of linear and castor oil cross-linked PEG-based polyurethane elastomers. J Mater Sci. 2011;46:2251-8.

13. Ristic I, Krakovsky I, Janic T, Cakic S, Miletic A, Jotanovic M, Radusin T. The influence of the nanofiller on thermal properties of thermoplastic polyurethane elastomers. J Therm Anal Calorim. 2018;134:895-901.

14. Datta J, Kasprzyk P, Błazek K, Włoch M. Synthesis, structure and properties of poly(ester-urethane)s obtained using bio-based and petrochemical 1,3-propanediol and 1,4-butanediol. J Therm Anal Calorim. 2017;130:261-76.

15. Oprea $S$. The effect of chain extenders structure on properties of new polyurethane elastomers. Polym Bull. 2010;65:753-66.

16. Korodi T, Marcu N, Tirnaveanu A. Polyurethane microcellular elastomers: 2. Effect of chain extender on the mechanical properties. Polymer. 1984;25:1211-3.

17. Firdaus FE. Chain extender on property relationships of polyurethane derived from soybean oil. World Acad Sci Eng Technol. 2011;5(9):758-61.

18. Pandya MV, Deshpande DD, Hundiwale DG, Kapadi UR. Cast polyurethanes: effect of chain extenders on thermal, mechanical, and dynamic mechanical properties. J Macromol Sci Chem. 1987;A24(5):527-38.

19. Oprea S. Effect of the diisocyanate and chain extenders on the properties of the cross-linked polyetherurethane elastomers. J Mater Sci. 2008;43:5274-81.

20. Liaw D-J. The relative physical and thermal properties of polyurethane elastomers: effect of chain extenders of bisphenols, diisocyanate, and polyol structures. J Appl Polym Sci. 1997. https://doi.org/10.1002/(SICI)1097-4628(19971114)66:7\%3c12 51:AID-APP5\%3e3.0.CO;2-F.

21. Auten KL, Pentrovic ZS. Synthesis, structural characterization, and properties of polyurethane elastomers containing various degrees of unsaturation in the chain extenders. J Polym Sci B Polym Phys. 2002;40:1316-33.

22. Ahn TO, Jung SUK, Jeong HM, Lee SW. The properties of polyurethanes with mixed chain extenders and mixed soft segments. J Appl Polym Sci. 1994;51:43-9.

23. Rogulska M, Kultys A, Lubczak J. New thermoplastic polyurethane elastomers based on aliphatic aromatic chain extenders with different content of sulfur atoms. J Therm Anal Calorim. 2015;121:397-410.

24. Rogulska M, Kultys A. Aliphatic polycarbonate-based thermoplastic polyurethane elastomers containing diphenyl sulfide units. J Therm Anal Calorim. 2016;126:225-43.

25. Kultys A, Puszka A. Transparent poly(thiourethane-urethane)s based on dithiol chain extender. J Therm Anal Calorim. 2014;117:1427-39.

26. Oprea S. Novel quinoline-based polyurethane elastomers. The effect of the hard segment structure in properties enhancement. J Polym Res. 2012. https://doi.org/10.1007/s10965-011-9767-3.

27. Hazmi ASA, Pauzi NNPN, Maurad ZA, Abdullah LC, Aung MM, Ahmad A, Salleh MZ, Tajau R, Mahmood MH, Saniman SE. Understanding intrinsic plasticizer in vegetable oil-based polyurethane elastomer as enhanced biomaterial. J Therm Anal Calorim. 2017;130:919-33.

28. Datta J, Kosiorek P, Włoch M. Synthesis, structure and properties of poly(ether-urethane)s synthesized using a tri-functional oxypropylated glycerol as a polyol. J Therm Anal Calorim. 2017;128:155-67.

Publisher's Note Springer Nature remains neutral with regard to jurisdictional claims in published maps and institutional affiliations. 